Abstract

\title{
The Effect of Medium Type and Subculture Frequency on the Formation of Friable Embryogenic Callus for Coconut Cell Suspension Culture ${ }^{+}$
}

\author{
Eveline Y. Y. Kong *, Julianne Biddle and Steve W. Adkins \\ School of Agriculture and Food Sciences, The University of Queensland, Gatton Campus, Gatton, Qld 4343, \\ Australia; julianne.biddle@uq.edu.au (J.B.); s.adkins@uq.edu.au (S.A.) \\ * Correspondence: eveline.kong@uqconnect.edu.au \\ + Presented at the third International Tropical Agriculture Conference (TROPAG 2019), Brisbane, Australia, \\ 11-13 November 2019.
}

Published: 3 January 2020

\begin{abstract}
Coconut, a multipurpose palm, is facing increasing demand for its fruit as well as the pressure from industries to produce coconut-derived products. However, coconut production has been declined, and about half of the planted palms are facing senility in the producing countries. This condition will not be alleviated with the continual practice of traditional breeding methods which produces only one seedling per fruit. Hence, coconut cloning by somatic embryogenesis is the focus of the present work. Although this has been attempted for over 60 years, improvements are still needed to increase the production rate. Therefore, a cell multiplication step to increase the production of embryogenic cells through cell suspension culture is proposed because the establishment of cell suspension culture and its regeneration in oil palm and date palm have been achieved with great success. Consequently, the establishment of coconut cell suspension culture is anticipated to bring a leap in production. The initial plant material for the initiation of cell suspension culture is friable embryogenic callus. As the nature of the embryogenic callus is often compact, the effect of medium type and subculture frequency on the induction of friable embryogenic coconut callus was studied. Based on the results, their effects on the friable embryogenic callus formation were minimal, so the formation is likely to depend on other factors. There were however effects on the callus and embryogenic callus formed and it was found that those cultures in solid media require less subculture than those in liquid media.
\end{abstract}

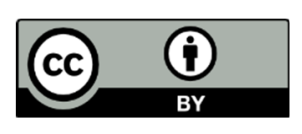

(C) 2020 by the authors. Licensee MDPI, Basel, Switzerland. This article is an open access article distributed under the terms and conditions of the Creative Commons Attribution (CC BY) license (http://creativecommons.org/licenses/by/4.0/). 